\title{
Comparative study of hydroxyapatite and octacalcium phosphate coatings deposited on metallic implants by PLD method
}

\author{
W. Mróz - A. Bombalska · B. Budner · S. Burdyńska - M. Jedyński · A. Prokopiuk • \\ E. Menaszek • A. Ścisłowska-Czarnecka • A. Niedzielska • K. Niedzielski
}

Received: 22 November 2009 / Accepted: 15 June 2010 / Published online: 4 August 2010

(C) The Author(s) 2010. This article is published with open access at Springerlink.com

\begin{abstract}
The aim of the presented study was an analysis of two apatite coatings: hydroxyapatite (HA) and octacalcium phosphate (OCP) as coatings materials for metallic implants. Both layers were deposited by means of the PLD method. As a target material, synthetic, powdered and pressed hydroxyapatite was used. HA was deposited on 316 steel substrate in two temperature ranges for obtaining different coatings: $150 \pm 30^{\circ} \mathrm{C}$ and $430 \pm 30^{\circ} \mathrm{C}$ for $\mathrm{OCP}$ and $\mathrm{HA}$, respectively. As an intermediate layer, the nanocrystalline diamond layer (NCD) was deposited. Examined calcium phosphate layers were tested for adhesion of osteoblast cell culture (MG-63). Analytical methods (AFM, FTIR) showed the usefulness of the PLD method for deposition of the apatite layers on metallic implants. Both examined layers showed biocompatibility with human osteoblast
\end{abstract}

W. Mróz · A. Bombalska (凶) · B. Budner · S. Burdyńska ·

M. Jedyński · A. Prokopiuk

Institute of Optoelectronics, Military University of Technology,

Gen. S. Kaliskiego str. 2, 00-908 Warszaw, Poland

e-mail: abombalska@wat.edu.pl

Fax: +48-666-89-50

E. Menaszek

Department of Cytobiology and Histochemistry,

Jagiellonian University, Medyczna 9 str., 30-688 Cracow, Poland

A. Ścisłowska-Czarnecka

Department of Anatomy, Academy of Physical Education,

Al. Jana Pawła II 78 str., 31-571 Cracow, Poland

\section{A. Niedzielska}

Faculty of Mechanical Engineering, Technical University

of Łódź, Żeromskiego 116 str., 90-924 Lodz, Poland

K. Niedzielski

Department of Orthopaedics, Polish Mother Memorial Hospital,

Medical University, Rzgowska 281/289 str., 93-338 Lodz, Poland cells and presented favorable conditions for their proliferation.

\section{Introduction}

Hydroxyapatite (HA) and other calcium phosphate ceramics $(\mathrm{Ca}-\mathrm{P})$ are widely used in medicine as coating materials for metallic implants because of their osteoconductive properties and biocompatibility with surrounding tissues.

The widest application, in coating of the metallic implants, was found for two phases of calcium phosphates: hydroxyapatite (HA) and octacalcium phosphate (OCP). OCP, in biological environment, is a precursor of HA and takes part in early stages of tissue calcification process [1-4]. In the past few years, OCP has drawn special attention as an alternative material to HA. In biological environment, it is more soluble than HA and as a coating material it would present faster resorption process and stimulation of the growth of the new bone [5-7]. In vitro tests showed correct adhesion, morphology and proliferation of the osteoblasts and fibroblasts on OCP coating [8]. Comparison of the materials composed of OCP, HA and Mn-HA showed positive in vitro results. In addition, the experiments also showed potential application of OCP as a biomimetic material for implant coating [9].

Between a metallic implant and an apatite layer, a transition layer is being introduced. Its role is to combine the materials with different structural and mechanical properties. One of these materials is nanocrystalline diamond (NCD). NCD layers turned to be highly resistive to bacteria colonization as compared to medical steel or titanium, which has an important advantage considering biomedical application of this material [10], especially in implantology where implant infection might lead to its rejection. NCD is applied 
in covering surgical tools in stomatology, cardiology, orthopaedics, vascular disease and also in biosensors in tissue engineering and implantology [11-18].

Comparative analysis of two apatite materials was the aim of the present study. Both materials, deposited by the PLD method, were characterized before and after cell culturing with use of AFM imaging. Also the adhesive properties were tested with the CV test, and the influence on growth and proliferation of human osteoblastic cells MG-63 was estimated.

\section{Material and methods}

\subsection{Coatings deposition}

The calcium phosphate layers were deposited by means of an excimer ArF laser operating at $193 \mathrm{~nm}$ and pulse repetition of $5 \mathrm{~Hz}$. The laser pulse duration was $20 \mathrm{~ns}$ (FWHM), the laser fluence was about $7 \mathrm{~J} / \mathrm{cm}^{2}$ with pulse energy of $300 \mathrm{~mJ}$. The substrate surface was parallel to target surface, and the distance between them was $60 \mathrm{~mm}$ in the case of HA and $50 \mathrm{~mm}$ in the case of OCP. In the case of HA, the substrate temperature was $430 \pm 30^{\circ} \mathrm{C}$ and in the case of OCP the substrate temperature was $150 \pm 30^{\circ} \mathrm{C}$. The experiment was carried out with water vapor as a reactive atmosphere under a pressure of $30 \pm 5 \mathrm{~Pa}$. All layers were deposited on 316L stainless steel substrates with a $300 \mathrm{~nm}$ nanocrystalline diamond (NCD) buffer layer. The NCD layers were deposited by RF PACVD method described by Mitura et al. [19].

\subsection{Cell culture}

For the in vitro study, osteoblast-like cells MG-63 were seeded at the initial density of $7 \times 10^{3}$ cells per one milliliter of the medium, DMEM culture medium (PAA, Austria) supplemented with $10 \%$ fetal bovine serum, $1 \%$ L-glutamine and antibiotics: penicillin $(100 \mathrm{IU} / \mathrm{mL})$ and streptomycin $(100 \mu \mathrm{g} / \mathrm{mL})$. As a control tissue, culture polystyrene plates (TCPS) were used. Cultures were grown for 3 or 7 days at $37^{\circ} \mathrm{C}$ in a $5 \% \mathrm{CO}_{2}$ and $95 \%$ air atmosphere. After 3 and 7 days of incubation, cell adherence test was performed. Estimation of adherent cell mass was tested by crystalline violet absorption test, the CV test [20, 21]. For the CV test, performance cells cultured on studied materials were washed twice with PBS, fixed in $2 \%$ paraformaldehyde for $1 \mathrm{~h}$, stained with $0.5 \%$ crystal violet in $20 \%$ methanol for $5 \mathrm{~min}$, washed with water and dried. The dye was extracted from the cells with $100 \%$ methanol (POCh, Poland) and optical density (OD) was measured at $570 \mathrm{~nm}$. The absorbance is proportional to the cell mass, which adhered on the surface; the stronger the signal observed the greater the degree of the adherence.

\section{Results}

\subsection{Surface characterization after deposition process}

The phase composition of the obtained coatings was analyzed by means of an FTIR spectrometer (Perkin Elmer Spectrum GX) with a resolution of $4 \mathrm{~cm}^{-1}$. The spectra were summed 10 times in order to improve the signal-tonoise ratio. The topography of deposited layers was imaged by using AFM (Veeco Multimode IV SPM).

After deposition the OCP layer was characterized by well developed structure with round shaped grains having size of about $200 \mathrm{~nm}$. The height of the grains is diverse (Fig. 1), visible grains are homogeneously distributed over the surface. Phase composition pictured by AFM (Fig. 1(b)) shows one material phase. HA layer is composed of smaller grains as compared to OCP layer (Fig. 2).

Size of the grains is about $100 \mathrm{~nm}$ and their distribution is also morphologically homogeneous. In this case, the shape of grains is irregular. Phase composition indicates that more than one material phase is present in examined samples with overwhelming majority of HA phase.

Figure 3 depicts the absorption spectra (FTIR) of HA and OCP. The bands corresponding to $\mathrm{PO}_{4}$ group consist of two

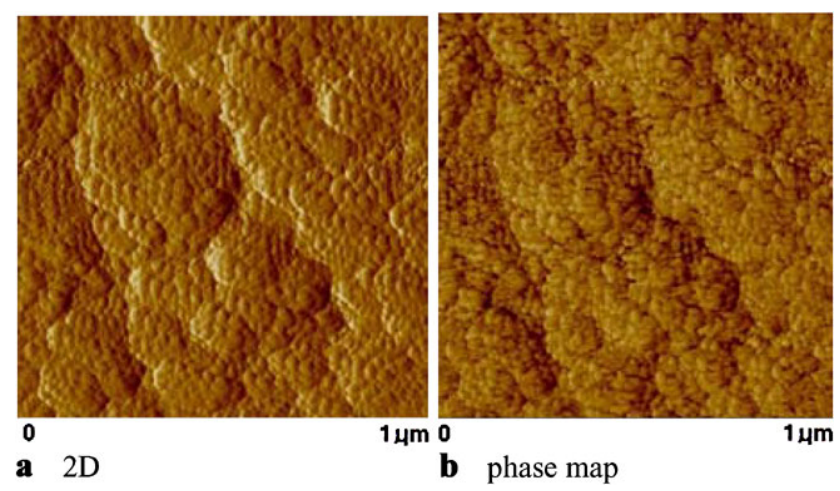

Fig. 1 OCP deposited on 316L stainless steel with NCD buffer layer: (a) 2D AFM image, (b) phase map

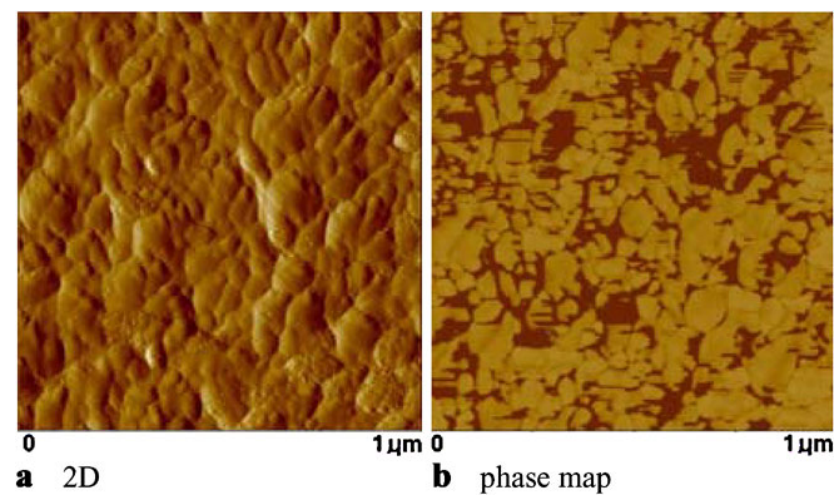

Fig. 2 HA deposited on 316L stainless steel with NCD buffer layer: (a) 2D AFM image, (b) phase map 


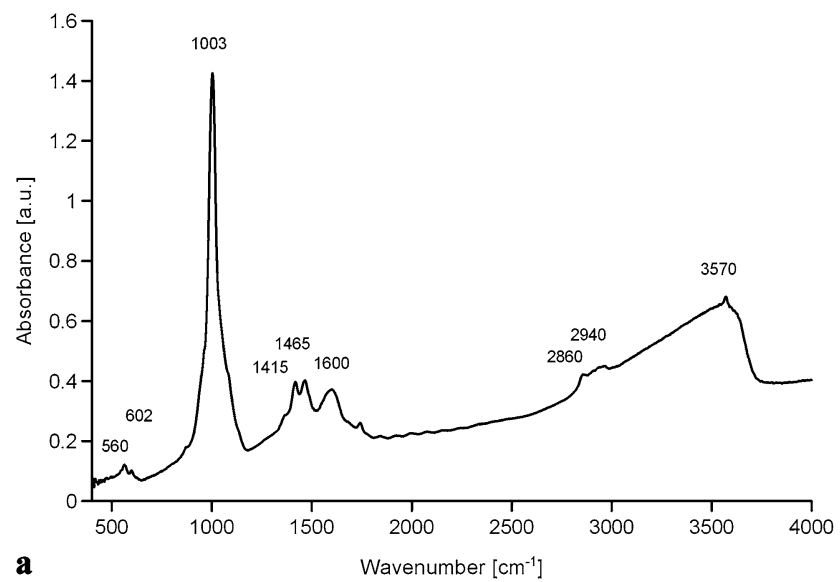

a

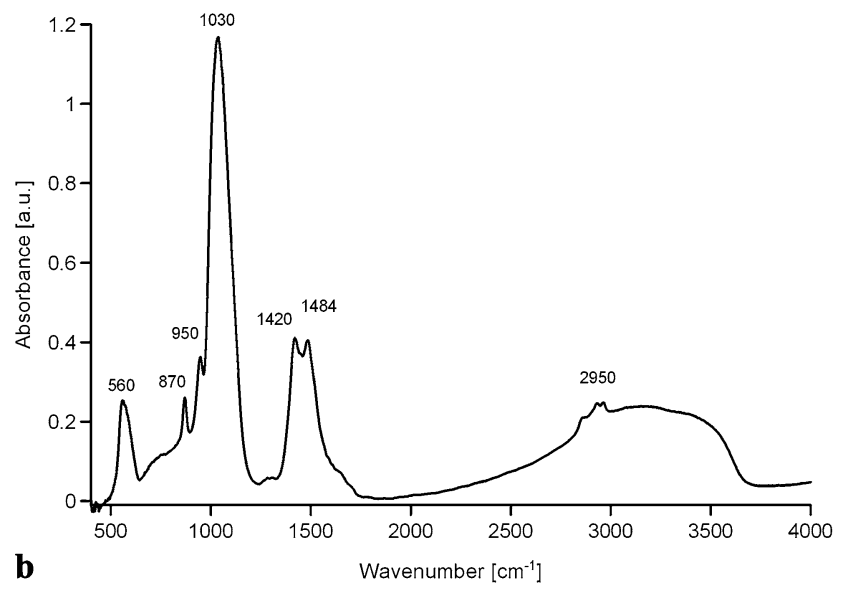

Fig. 3 Fourier spectra of deposited calcium phosphate layers: (a) HA, (b) OCP

main regions. The first one is characterized by two peaks at 560 and $602 \mathrm{~cm}^{-1}$, which reflect a bending mode. The second region is between 900 and $1200 \mathrm{~cm}^{-1}$. The peaks at 560 and $602 \mathrm{~cm}^{-1}$ are visible in the case of the HA layer; nevertheless, their intensity is low (Fig. 3(a)). In the case of OCP, the peaks at 560 and $602 \mathrm{~cm}^{-1}$ are higher and broadened, forming one band with a maximum at $560 \mathrm{~cm}^{-1}$ (Fig. 3(b)).This peak is higher than in the case of HA. The second region of $\mathrm{PO}_{4}$ mode in the $\mathrm{HA}$ spectrum has only one narrow peak at about $1003 \mathrm{~cm}^{-1}$. In the case of OCP, this region consists of two peaks attributed to $\mathrm{PO}_{4}$ vibrations, namely at 950 and $1030 \mathrm{~cm}^{-1}$. The peak at $1030 \mathrm{~cm}^{-1}$ is visibly broadened and shifted towards higher wavenumbers (Fig. 3(b)). Moreover, the thin nature of $\mathrm{PO}_{4}$ peak at $1003 \mathrm{~cm}^{-1}$ indicates that HA layer has polycrystalline structure and $\mathrm{OCP}$ is characterized by a less textured and ordered structure.

\subsection{Surface characterization after cell culture}

Surface of examined layers is visibly reconstructed both after 3 and 7 days of culturing. The HA surface is macrogranu-

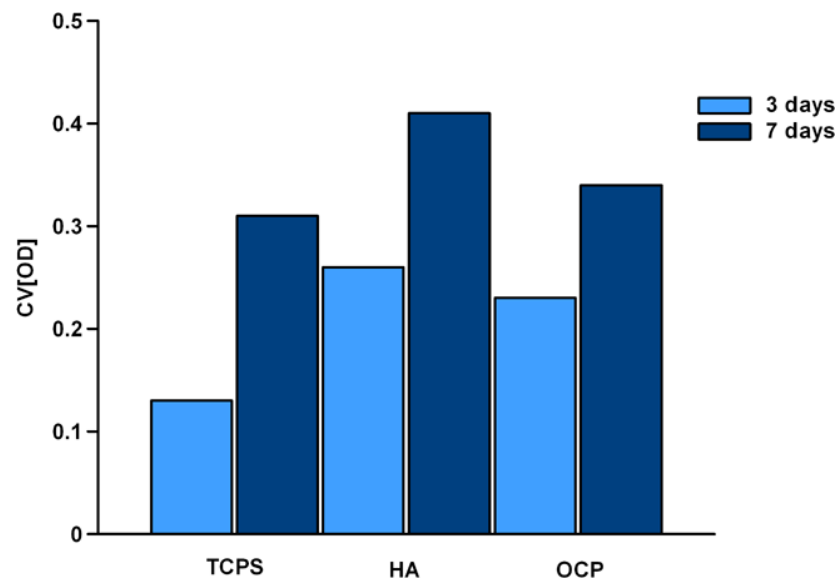

Fig. 4 Adhesion of the osteoblastic cells to the HA and OCP surface

lar, built out of triangular formations with material phase different than the initial one. These observations suggest biomimetic growth. In case of OCP, the surface is microgranular with uniform structure. Fine grains, uniformly distributed on the implant surface, are built out of one material phase.

Based on the CV test one can conclude that osteoblasts cultured on HA and OCP after 3 days of culturing possess similar adherence, substantially better compared to TCPS (Fig. 4). After 7 days of culturing, osteoblastic cells present better adhesion to HA than to OCP. Cells on both materials present correct morphology.

\section{Summary}

The PLD method was used for apatite layer deposition. Apatite layers were deposited from the same target material, namely hydroxyapatite. The FTIR and AFM diagnostics of the deposited layers characterized them as continuous, uniform structures with fine grains. For OCP, only one material phase was observed, while for HA, AFM phase image showed two, with HA as a major one. Both layers were appropriate for osteoblast cell culture. Both layers were visibly reconstructed. From macroscopic observations, based on topography analysis and the CV test, one can conclude that cells showed good adhesion to the surface. Cell adhesion to both apatites is similar after three days of culturing; however, after 7 days, effects are more diverse and optical density is higher for the HA material, pointing that this material is characterized as having better adhesion than OCP and TCPS.

Acknowledgements These experiments were partly financed by 358/ERA-NET/2009 and Eureka No. 57/N-Eureka/2007 projects.

Open Access This article is distributed under the terms of the Creative Commons Attribution Noncommercial License which permits any noncommercial use, distribution, and reproduction in any medium, provided the original author(s) and source are credited. 


\section{References}

1. W.E. Brown, N. Eidelman, B. Tomazic, Adv. Dent. Res. 1(2), 306 (1987)

2. P. Bodier-Houllé, P. Steuer, J.C. Voegel, Acta Crystallogr. D, Biol. Crystallogr. 54, 1377 (1998)

3. R.Z. Le Geros, J. Dent. Res. 53(1), 45 (1974)

4. M.S. Tung, W.E. Brown, Calcif. Tissue Int. 37(3), 329 (1985)

5. J. Zhang, G.H. Nancollas, J. Phys. Chem. 96, 5478 (1992)

6. A. Bigi, E. Boanini, G. Cojazzi, Cryst. Growth Des. 1, 239 (2001)

7. M.J. Arellano-Jimenez, R. Garcia-Garcia, J. Reyes-Gasga, J. Phys. Chem. Solids 70, 390 (2009)

8. G. Socol, P. Torricelli, B. Bracci, Biomaterials 25, 2539 (2004)

9. I.N. Mihailescu, P. Torricelli, A. Bigi, Appl. Surf. Sci. 248, 344 (2005)

10. W. Jakubowski, G. Bartosz, P. Niedzielski, Diam. Relat. Mater. 13, 1761 (2004)

11. S. Mitura, K. Mitura, P. Niedzielski, J. Achiev. Mater. Manuf. Eng. 16, 9 (2006)
12. W. Okrój, M. Kamińska, L. Klimek, Diam. Relat. Mater. 15, 1535 (2006)

13. X. Xiao, J. Wang, C. Liu, J. Biomed. Mater. Res. B, Appl. Biomater. 77B, 273 (2006)

14. L. Tang, C. Tsai, W.W. Gerberich, Biomaterials 16, 483 (1995)

15. D. Steinmueller-Nethl, F.R. Kloss, M.N.U. Haq, Biomaterials 27, 4547 (2006)

16. S. Wenmackers, P. Christiaens, M. Daenen, Phys. Status Solidi 202, 2212 (2005)

17. J.R. Retama, J. Hernando, B. Lopez-Ruiz, Langmuir 22, 5837 (2006)

18. P.S. Siew, K.P. Loh, W.C. Poh, Diam. Relat. Mater. 14, 426 (2005)

19. A. Mitura, E. Mitura, A. Mitura, Diam. Relat. Mater. 4, 302 (1995)

20. B. Płytycz, M. Chadzińska, Hodowla tkanek w immunologii, Wydawnictwo Naukowe (2004). (In Polish)

21. R.J. Gillies, N. Didier, M. Denton, Anal. Biochem. 159, 1 (1986) 